Article

\title{
Environmental and biological monitoring of formaldehyde inside a hospital setting: A combined approach to manage chemical risk in workplaces
}

\author{
Oriana Motta, ${ }^{1,2}$ Bruno Charlier, ${ }^{1,2}$ Francesco De Caro,,${ }^{1,2}$ Albino Coglianese, ${ }^{1}$ \\ Federica De Rosa, ${ }^{2}$ Giuseppina Moccia, ${ }^{1,2}$ Concetta Pironti, ${ }^{2}$ Mario Capunzo,,${ }^{1,2}$ Anna Borrelli, ${ }^{2}$ \\ Amelia Filippelli, ${ }^{1,2}$ Viviana Izzo ${ }^{1,2}$ \\ ${ }^{1}$ Department of Medicine, Surgery and Dentistry "Scuola Medica Salernitana”, University of Salerno, Baronissi \\ (SA); 'University Hospital "San Giovanni di Dio e Ruggi d'Aragona”, Salerno, Italy
}

\begin{abstract}
Background: The safety of healthcare workers exposed to formaldehyde remains a great matter of concern for healthcare management units. This work aimed at describing the results of a combined monitoring approach (environmental and biological) to manage occupational exposure to formaldehyde in a hospital setting.

Design and Methods: Environmental monitoring of working spaces and biological monitoring of urinary formaldehyde in 16 exposed healthcare workers of the Anatomic Pathology Unit of a University Hospital in Southern Italy was performed on a fouryear timescale (2016-2019).

Results: Values of aero-dispersed formaldehyde identified were on average low; although workers' urinary formaldehyde levels were also minimal, the statistical analysis highlighted a slight weekly accumulation.

Conclusions: Our data confirm that both environmental and biological monitoring are important to identify risk situations, in particular when values of hazardous compounds are below the accepted occupational exposure levels.
\end{abstract}

\section{Introduction}

Formaldehyde (FA) is a widespread chemical substance having formula $\mathrm{HCHO}$, commercially available as an aqueous solution known as formalin, containing 30-50\% FA with methanol as a stabilizer to prevent its polymerization. Formaldehyde solution is a clear colourless liquid with a pungent and irritating smell ${ }^{1}$ and is mainly used in the canning industry, leather tanning, embalming, fabric manufacture, and as a biocide in the food industry. ${ }^{2}$ Formaldehyde is endogenously produced in living organisms as a by-product of serine, glycine, methionine, and various other amino acids metabolism. Endogenous levels of metabolic FA production range from 3 to $12 \mathrm{ng} / \mathrm{g}$ of tissue; ${ }^{3}$ plasmatic concentration of FA in humans is estimated to be $c a$. $2.5 \mathrm{ppm}$. Exogenous FA does not accumulate in the body and is rapidly eliminated from human plasma; a biological half-life of this molecule of only 1-1.5 min seems to be responsible for preventing FA systemic distribution in the human body. ${ }^{4,5}$ Indeed, no increase in FA blood concentration has been observed in either humans, rats, or monkeys after acute exposure at concentrations of $1.9 \mathrm{ppm}\left(2.3 \mathrm{mg} / \mathrm{m}^{3}\right), 6 \mathrm{ppm}$ $\left(7.2 \mathrm{mg} / \mathrm{m}^{3}\right)$, and $14.4 \mathrm{ppm}\left(17.3 \mathrm{mg} / \mathrm{m}^{3}\right)$ of gaseous FA, respectively. This can be explained with both formaldehyde main deposition in the respiratory tract and rapid metabolism. ${ }^{6}$

Possible ways of exposure to exogenous FA are ingestion, inhalation, skin absorption, and blood exchange. Once absorbed, FA is quickly metabolized by almost all body tissues and converted into a non-toxic chemical compound called formate, which is then expelled with urine. Formaldehyde can also be converted into carbon dioxide and exhaled out of the body via pulmonary expiration (Figure 1).

Despite the rapid elimination from the human body, the exposure to exogenous FA sources, both indoors and outdoors, poses a significant threat to human health, and the interest in this topic has been boosted by the current legal statement that has labeled FA as a "Carcinogen for man" - category 1.7,8

Workers employed in industries producing FA or FA-containing substances, along with laboratory technicians and certain healthcare professionals, may be exposed to higher levels of this molecule compared to the general public. These workers can suffer from harmful effects from breathing FA gas or vapor or by absorbing liquid containing FA through the skin. The site of direct contact (eyes, nose, throat, and skin), in fact, quickly reacts with FA, which can destroy protective skin oils causing dryness, flaking, and dermatitis. High levels of FA (5-30 ppm) can severely irritate the lungs, causing chest pain and breathing problems. Humans perceive FA smell at a concentration of about $0.5-1.0$ $\mathrm{ppm}$, followed by sensory irritation $(>2.0 \mathrm{ppm})$ of nose, throat, and eyes, with eye irritation accepted as the most sensitive endpoint. Both hepatotoxicity and neurotoxicity have also been considered as potential effects of formaldehyde exposure. . $^{9,10}$

In hospital units, FA in aqueous solution, or formalin, is used for collection and transport of tissues derived from surgical interventions and biopsies in operating rooms and biopsy sampling clinics (endoscopy, radiology, etc.) and as a fixative in pathologi-

Health workers' regular exposure to formaldehyde may be responsible for long-term health issues; unfortunately, threshold limits of this compound are not harmonized between different government agencies. The combination of environmental and biological monitoring thus becomes an invaluable tool to preserve worker's safety and effectively assess chemical risk in hospital settings. 
cal anatomy for its unique properties of preserving cell and tissue morphology. National and international guidelines recommend the use of buffered formalin for histological, immunohistochemical, and molecular (gene mutation) examinations. In addition, all validated protocols related to histochemical, immunohistochemical, and molecular investigations are currently standardized on formalin-fixed tissues. ${ }^{11}$ Thus, monitoring environmental FA levels to which health workers are exposed through the use of an efficient methodology to measure biological levels of FA is of crucial importance to prevent organism overload and potential multi-organ damage.

The main goal of this work was to describe operational strategies aimed at reducing the risk related to FA exposure in hospital settings by using an approach combining Environmental and Biological Monitoring. FA measurements based on this combined method were performed on a four-year timescale at a University Hospital in Southern Italy, where environmental and urinary FA levels of 16 employees working at the Anatomic Pathology Unit were evaluated.

\section{Design and Methods}

\section{Building and facilities}

The Anatomic Pathology Unit is located on the ground floor of the clinical building and has five rooms for specimen treatment, a corridor, and physicians' rooms. In all rooms, a ventilation system is installed, consisting of down flown ventilation with conditioned air flowing into the room from the ceiling and extraction units in the walls; openable windows to the outside of the building are present. Formaldehyde is mainly used in a $23 \mathrm{~m}^{2}$ room, equipped with a chemical hood and an aspirated cupboard for the storage of anatomical samples.

At the beginning of our monitoring activity (2016), sampling concerned all department rooms to evaluate FA dispersion also in locations not directly affected by the processing of histological samples. In the second, third, and fourth monitoring campaigns $(2017,2018,2019)$ only the processing room was analyzed.

\section{Biological monitoring of urinary formaldehyde}

Workers' urinary FA was measured using High Performance Liquid Chromatography (HPLC) coupled with a UV-Visible detector (HPLC-UV). A CE-IVD (European Certification - in vitro Diagnostics) kit provided by the "Eureka Lab Division" was used. According to the manufacturer, urinary samples were derivatized with a chemical reagent supplied with the kit and incubated at $70^{\circ} \mathrm{C}$ for $15 \mathrm{~min}$. Then, five-hundred microliters of HPLC-grade water were added to the sample and $50 \mu \mathrm{l}$ of the resulting mixture was directly injected into the HPLC system.

The chromatographic separation was achieved by RP-HPLC, performed on a Waters 1525 Model Binary Pump System equipped with a multi $\lambda$ Fluorescence detector (Model 2475), a Photodiode Array detector (Model 2998), and an Autosampler (Model 2707) (Waters, Milford, MA, USA). Samples in the autosampler were at RT and a column oven was used to maintain column temperature at $30^{\circ} \mathrm{C}$. Breeze software 2.0 (Waters) was used for peak analysis, integration, and to calculate the linear regression of the calibration curve. Chromatographic analysis was carried out on a Poroshell $120 \mathrm{EC}^{-\mathrm{C}_{18}}(50 \times 4.6 \mathrm{~mm}, 2.7 \mu \mathrm{m})$ column (Agilent). The mobile phase was included in the commercial kit. The separation was

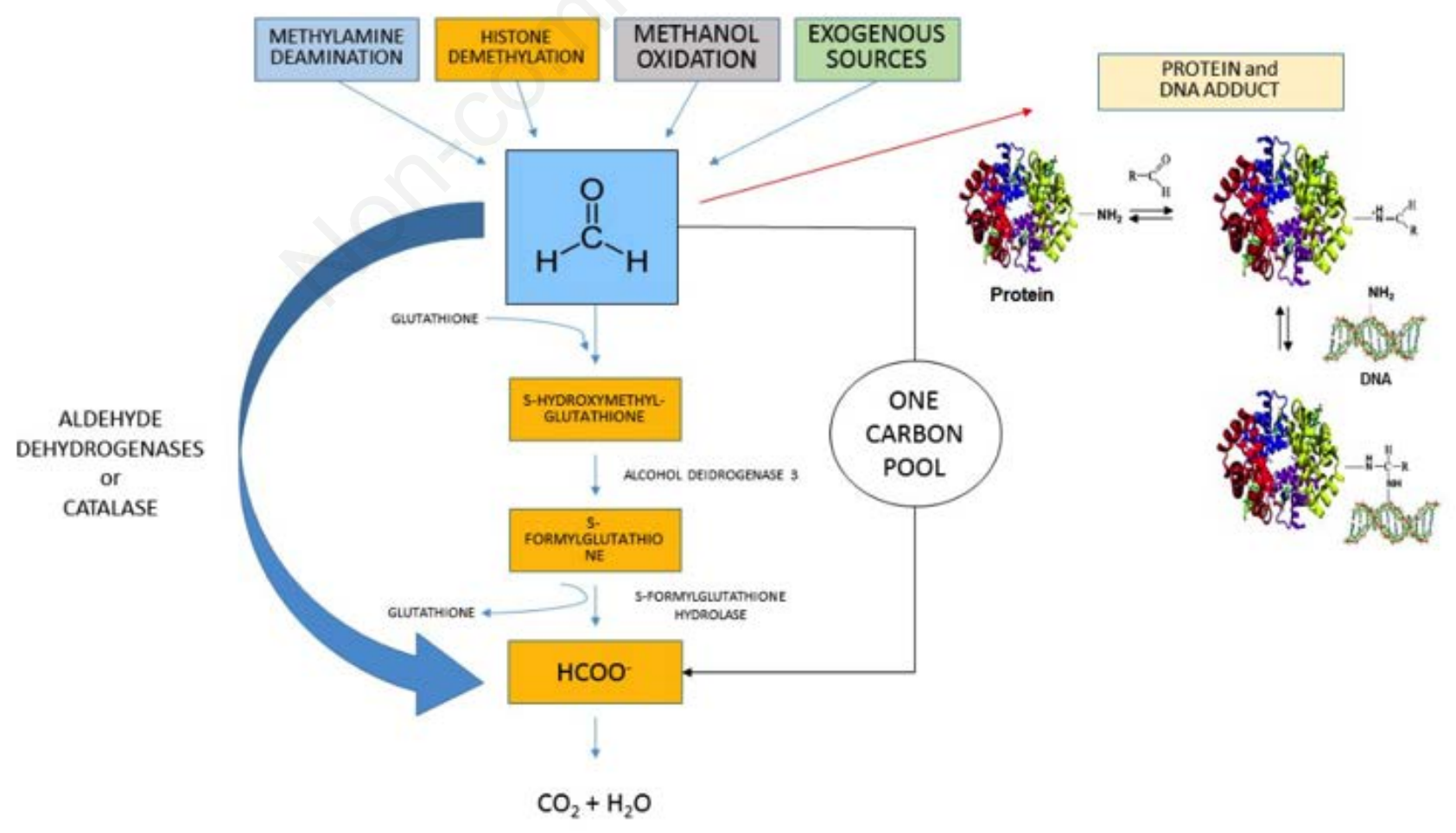

Figure 1. Formaldehyde pathway and metabolism. 
achieved by isocratic elution with a flow rate of $1.2 \mathrm{ml} \mathrm{min}$. Analytes were revealed with a UV detector set at $\lambda=385 \mathrm{~nm}$.

\section{Environmental monitoring of formaldehyde}

Formaldehyde environmental monitoring was performed on selected fixed locations by both:

1) active sampling using chemo-adsorbent tubes (following NIOSH 2016 method), with a properly calibrated pump, provided by Aquaria srl (Lacchiarella, MI, Italy), and whose flow was set to a constant value of $1 \mathrm{~L} / \mathrm{min}$ throughout the sampling period. The sampling flow rate was checked continuously by a fluxometer. ${ }^{12,13}$ Four samples per working day and three measurements for each sample were analyzed and mean values were reported. The sampling procedure requires a known volume of sample air (from 1 to 15 litres) to be passed through an acidified silica gel coated with 2,4-dinitrophenylhydrazine (DNPH). Formaldehyde reacts with the DNPH producing the corresponding hydrazone. After the sampling phase, tubes were closed with caps, transported, and stored in glass containers in refrigerated systems maintained at a controlled temperature.

2) diffusive (passive) sampling, to evaluate average concentration values (TLV-TWA $8 \mathrm{~h}$ per working day), by exposing diffusive samplers (RING devices provided by Aquaria srl) containing a silica gel cartridge coated with 2,4-dinitrophenylhydrazine (DNPH) in one selected location. This method is indicated for long-term monitoring. ${ }^{14-18}$ Three measurements were realized for each determination and the average value was reported. At the end of the sampling phase, tubes were closed with the appropriate caps and stored in glass containers in refrigerated systems maintained at a controlled temperature. The mass concentration $\mathrm{C}\left(\mu \mathrm{g} / \mathrm{m}^{3}\right)$ of passive samplers was calculated with the manufacturer's uptake rate of $92 \mathrm{ml} / \mathrm{min}$, and using the following formula:

$$
\mathrm{C}\left(\mu \mathrm{g} / \mathrm{m}^{3}\right)=\operatorname{mass}(\mu \mathrm{g}) / 10^{-6} \times \mathrm{P}(\mathrm{ml} / \mathrm{min}) x \text { time }(\mathrm{min})
$$

This equation can be directly derived from Fick's first law considering that the mass of the analyte is sorbed by diffusion, ${ }^{16}$ time represents the time of exposition of the sampler and $\mathrm{P}$, the diffusive uptake rate, is dependent only on the diffusion coefficient of the given analyte and on the geometry of the diffusive sampler used.

The limit of detection (LOD) of this methodology was threetimes the standard deviation of the blank values (as reported in EN 13528-2) and accuracy was calculated as the $2 \sigma$ deviation of the absolute differences of the individual sample values compared to the mean in triplicate samples. ${ }^{19}$

Formaldehyde sampled with both active and passive samplers was detected according to the method described by NIOSH 2016, ${ }^{20}$ which involves an organic extraction with acetonitrile and subsequent analysis by HPLC. Analyses were performed on an HPLC instrument with a PDA detector set at $385 \mathrm{~nm}$ supplied by Waters ${ }^{\circledR}$ Corporation and an Ascentis ${ }^{\circledR} \mathrm{C} 18$ analytical column (4.6 mm x $150 \mathrm{~mm}, 3 \mu \mathrm{m})$; chromatographic elution conditions consisted in a mobile phase composed of $45 \%$ acetonitrile $/ 55 \%$ water $(\mathrm{v} / \mathrm{v})$ and a flow rate of $1.0 \mathrm{ml} / \mathrm{min}$. For data analysis, Breeze ${ }^{\circledR} 2.0$ software, supplied by Waters ${ }^{\circledR}$, was used. Extraction was performed by adding $3 \mathrm{ml}$ of acetonitrile to the vial.

Analytic grade acetonitrile and $99.9 \%$ pure formaldehyde-2,4dinitrophenylhydrazone (FA-2,4-DNPH) were purchased from Sigma-Aldrich (St. Louis, MO, USA). For calibration, a known amount of FA-2,4-DNPH was weighed and diluted in acetonitrile; from this stock, dilutions in acetonitrile were prepared for calibration in a range of 0.23 to $37 \mu \mathrm{g}$ per sample.

RING diffusion samplers and tubes for active sampling were provided by Aquaria ${ }^{\circledR}$ srl. Water and acetonitrile (ACN) were purchased from Romil ${ }^{\circledR}$ (Waterbeach, Cambridge, UK) and were all HPLC grade.

\section{Statistical analyses}

Data were expressed as means \pm SD per year, as median and range of values (min - max); comparisons between the different years of collection were analyzed and comparisons of the values of the different work shifts were analyzed. These analyses were performed considering the differences between FA levels measured during working days (intra- and inter-day backlog) and basal values (start of weekly work shift).

\section{Results}

\section{Environmental monitoring}

To maintain a safe and healthy workplace for employees working with hazardous chemicals such as FA, it is important to minimize exposure to this compound. To this purpose, the maximum air concentration of the chemicals that may still be considered safe has been defined as time-weighted averages measured over $8 \mathrm{~h}$ (TWA) and short-term exposure limits (STEL) for a $15 \mathrm{~min}$ period (TLVCeiling). However, these occupational exposure limits (OELs) can be set at World level, at European level, at national level or by companies themselves and, therefore, regulations for setting OELs may deeply vary. Moreover, OEL can be estimated by different methods, which may result in a variety of OELs. Table 1 reports the main Threshold Limit Values for FA proposed by different

Table 1. Threshold limit values for formaldehyde provided by main government agencies.

\begin{tabular}{lcc} 
Organization/legal of countries & Type & Concentration (ppm) \\
Occupational Safety and Health Administration (OSHA-USA) & TWA & 0.75 \\
& STEL & 2.0 \\
American conference of Governmental Industrial Hygienists (ACGIH-USA) & TWA & 0.1 \\
& STEL & 0.3 \\
National Institute for Occupational Safety and Health (NIOSH) & TWA & 0.016 \\
World Health Organization (WHO) & STEL & 0.1 \\
\hline Scientific Committee on Occupational Exposure Limits UE (SCOEL) & STEL & 0.08 \\
& TWA & 0.3 \\
\hline
\end{tabular}

TWA, time-weighted averages measured over $8 \mathrm{~h}$; STEL, short-term exposure limits. 
international organizations.

It is important to underline that these limits do not constitute a clear dividing point between non-dangerous and harmful concentration, but they only indicate the concentrations of the airborne substances to which it is believed that most workers can remain exposed for eight-hours daily, forty hours a week, forty-eight weeks a year, without suffering of adverse health effects.

The environmental monitoring campaign in the Anatomic Pathology Unit was aimed at evaluating the amount of airborne FA in the various environments, and the ability of FA to diffuse between adjacent rooms. Twenty sampling areas were selected in the structure to evaluate the concentration of FA and identify the possible diffusive path of FA in the environments adjacent to the histological sample processing room. In Table 2 the results of four monitoring campaigns at the Anatomic Pathology Unit of the Hospital are reported. During the first campaign (2016), we randomized the sampler location to identify the sampling sites that could be representative of the general pollution conditions, whereas sampling was focused on a fixed location during the next campaigns (2017-2018-2019). Sampling was performed by both passive and active methods, as described in the Materials and Methods Section to verify compliance with both TWA and STEL limits.

As expected, the active sampling method returned a higher concentration than the passive method. However, all active and passive measurements showed compliance with the OSHA and ACGIH exposure limits, but not always with the lowest NIOSH REL. Only a few active measurements exceeded NIOSH STEL, mainly in correspondence with the sampling site located near the open trash bin next to the fume hood.

These results were in agreement with the inaccurate and erroneous workers' practice to throw in the open bin gloves and paper towels used to clean FA contaminated surfaces, thus leading to the evaporation of residual formaldehyde in the environment.

Moreover, since it is well known that environmental factors such as temperature and relative humidity may influence the performances of passive samplers, we always checked these parameters using a calibrated instrument for measuring environmental parameters; values are reported in Table 1 and show minimal variations for each sampling period. In particular, the temperature was in the range of $25-28^{\circ} \mathrm{C}$ and the relative humidity was in the range of $38-52 \%$. In these conditions, no adverse effect on recovery is expected.

Noteworthy, the percentage of non-compliance, calculated as the number of measurements above the OEL, decreases from the first to the last monitoring campaign from $50 \%$ to $7 \%$ for the active measurements and from $12.2 \%$ to $0 \%$ for the passive one. This marked improvement in environmental conditions mainly depend- ed on the employees who, despite no structural or technical changes in the work environment had been realized, had perceived the importance of their actions in limiting the spread of formaldehyde, and devoted greater attention to the actions they carried on daily.

\section{Biological monitoring}

Each biological monitoring campaign included three withdrawal times, more specifically on Monday morning at the beginning of the weekly shift (T0), Monday evening at the end of the daily shift (T1), and Friday evening at the end of the weekly shift. This timing allowed evaluating both the intra-day exposure and the weekly backlog (inter-day exposure). By analysing urinary FA concentrations at the beginning of the working week, it was also possible to evaluate whether any abnormal level of FA was related to an occupational rather than an accidental exposure, for example during the weekend. Biological monitoring started in Fall 2016 and was repeated every six months, in parallel with environmental monitoring. Urine samples were collected, labeled, and stored at $20^{\circ} \mathrm{C}$ until analysis.

A statistical comparison of the values obtained in the four years analysed (Figure 2), shows that the highest average value was measured in $2018(0.75 \mathrm{mg} / \mathrm{L})$. The analysis of variance (ANOVA) shows that in 2018 the values deviate less from the mean value. Medians reflect this trend, with higher values in 2018 and lower in the second half of 2017.

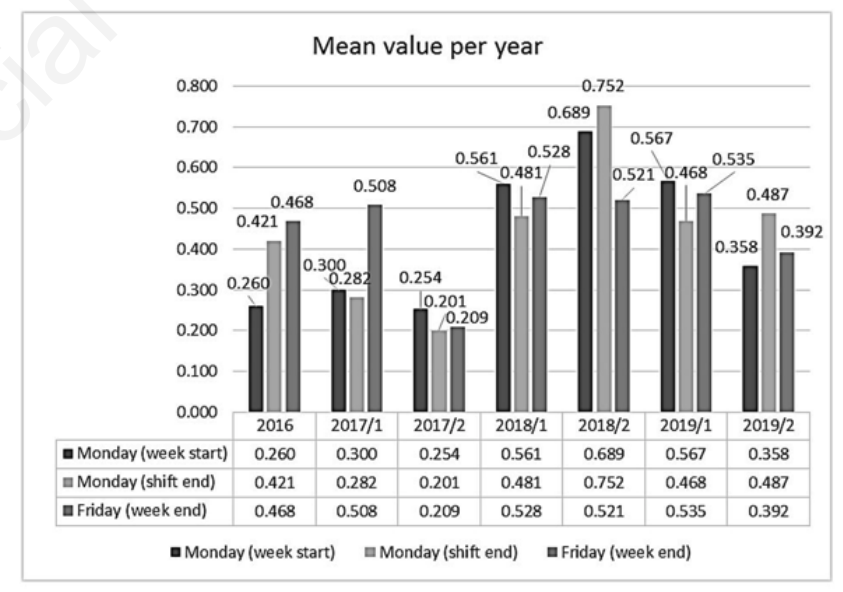

Figure 2. Average values of the three sampling times obtained for each monitoring campaign.

Table 2. Formaldehyde concentration (ppm) detected in the Anatomic Pathology Unit of the University Hospital "San Giovanni di Dio e Ruggi d 'Aragona" in Salerno (Italy) in four years.

\begin{tabular}{|c|c|c|c|c|c|c|c|}
\hline Year & $\begin{array}{l}\text { RH } \\
(\%)\end{array}$ & $\begin{array}{c}\text { Temperature } \\
\left({ }^{\circ} \mathrm{C}\right)\end{array}$ & $\begin{array}{l}\text { Sampling method } \\
\text { (active/passive) }\end{array}$ & n. samples & $\begin{array}{l}\text { Averages } \\
\text { (ppm) }\end{array}$ & $\begin{array}{l}\text { Range } \\
(\mathrm{ppm})\end{array}$ & $\begin{array}{c}\text { Non-compliance } \\
(\%)\end{array}$ \\
\hline 2016 & $46 \pm 6$ & $25.7 \pm 1.0$ & $\begin{array}{l}\text { Passive } \\
\text { Active }\end{array}$ & $\begin{array}{l}15 \\
24\end{array}$ & $\begin{array}{l}0.0098 \\
0.0790\end{array}$ & $\begin{array}{l}0.0033-0.0400 \\
0.0220-0.1390\end{array}$ & $\begin{array}{l}12.2 \\
50.0\end{array}$ \\
\hline 2017 & $42 \pm 4$ & $25.2 \pm 0,8$ & $\begin{array}{l}\text { Passive } \\
\text { Active }\end{array}$ & $\begin{array}{l}30 \\
48\end{array}$ & $\begin{array}{l}0.0013 \\
0.0430\end{array}$ & $\begin{array}{l}0.0004-0.0050 \\
0.0290-0.1587\end{array}$ & $\begin{array}{c}0 \\
22.2\end{array}$ \\
\hline 2018 & $45 \pm 7$ & $25.8 \pm 2.0$ & $\begin{array}{l}\text { Passive } \\
\text { Active }\end{array}$ & $\begin{array}{l}27 \\
56\end{array}$ & $\begin{array}{l}0.0006 \\
0.0380\end{array}$ & $\begin{array}{c}0.00014-0.00105 \\
0.0134-0.1250\end{array}$ & $\begin{array}{c}0 \\
10.0\end{array}$ \\
\hline 2019 & $44 \pm 7$ & $27.8 \pm 2.0$ & $\begin{array}{l}\text { Passive } \\
\text { Active }\end{array}$ & $\begin{array}{l}20 \\
52\end{array}$ & $\begin{array}{l}0.0005 \\
0.0280\end{array}$ & $\begin{array}{c}0.00018-0.00098 \\
0.0060-0.1050\end{array}$ & $\begin{array}{c}0 \\
7.0\end{array}$ \\
\hline
\end{tabular}


Table 3 shows the average values obtained in each single monitoring campaign. The reference value used to identify potential risk for the workers is, according to the guidelines of the Italian Association of Industrial Hygienists (AIDII) (https://www.aidii.it/), $5.6 \mathrm{mg} / \mathrm{L}$. As evident from Figure 2 and Table 3, values were always far below the accepted threshold value. However, it is worth noting that in 2016 and the first campaign of 2017, the average of the values recorded on Friday evening was higher than that of Monday end shift, thus suggesting the tendency, albeit minimal, to a weekly stack.

In the second half of 2017 and in 2018, the three sampling times report comparable values; this can be attributed to exposure of workers to outside FA sources, not imputable to hospital workspace, or, likely, to a subjective endogenous level of FA.

An analysis focusing on single workers' values trend, measured over the four years, has been shown in Figure 3. In 2016, $61.5 \%$ of the values, measured on Friday at the end of the working shift (T2), increased compared to the values measured on Monday evening at the end of the working shift (T1), while the intra-day measurements of the first working day (T0 vs T1) highlighted an increase in FA values in $69.2 \%$ of workers. In 2017, the trend was similar. In 2018, we observed an increase in T1 vs T2 for 50\% of workers, with values more than doubled in $18.7 \%$ of cases. In the T0 vs T1 measurements, on the other hand, an increase in FA values was found in only $25 \%$ of workers.
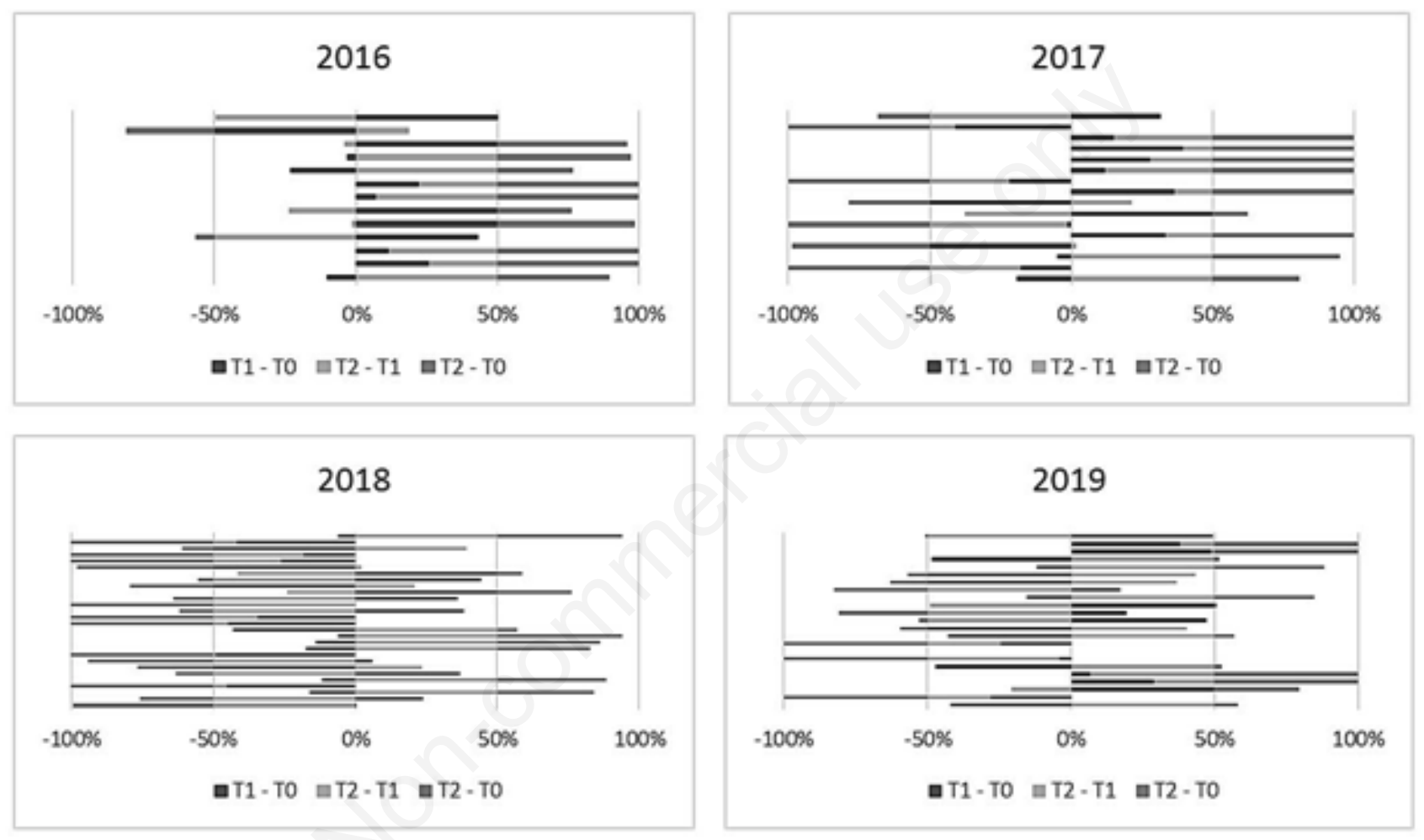

Figure 3. Analysis performed over four years of values trend for each worker. Values expressed in mg/l.

Table 3. Formaldehyde values measured in each biological monitoring campaign for workers in the Anatomic Pathology Unit of the University Hospital "San Giovanni di Dio e Ruggi d 'Aragona" in Salerno (Italy). Values expressed in mg/l.

\begin{tabular}{lcccc} 
Year & Mean \pm SD & Median & Range (min-max) \\
2016 & $0.39 \pm 0.23$ & 0.33 & 0.03 & 0.93 \\
$2017 / 1$ & $0.34 \pm 0.25$ & 0.27 & 0.06 & 0.99 \\
\hline $2017 / 2$ & $0.22 \pm 0.14$ & 0.22 & 0.03 & 0.80 \\
$2018 / 1$ & $0.52 \pm 0.17$ & 0.48 & 0.22 & 1.04 \\
$2018 / 2$ & $0.65 \pm 0.39$ & 0.56 & 0.13 & 1.89 \\
$2019 / 1$ & $0,52 \pm 0,23$ & 0.45 & 0.06 & 0.91 \\
\hline $2019 / 2$ & $0.41 \pm 0.32$ & 0.38 & 0.04 & 1.31 \\
\hline
\end{tabular}




\section{Discussion}

Starting January 2016, FA re-classification as a "carcinogenic substance" has urged employers to find solutions to limit workers' exposure to this harmful compound. Doubts and fears among workers due to the risk associated with FA professional exposure, are rightful. Short-term health effects are variable depending on the subject's sensitivity to the compound and include irritative pathologies mainly affecting upper and lower airways. ${ }^{21}$

In Italy, a maximum exposure limit for FA in working and living environments was initially set, as early as 1983, at a concentration of $0.1 \mathrm{ppm}\left(124 \mu \mathrm{g} / \mathrm{m}^{3}\right){ }^{22}$ European Union has definitively classified FA as a carcinogenic substance (category 1B) with the EU regulation No. 895/2014, concerning the registration, evaluation, authorization, and restriction of chemical substances (REACH). Italy has fully adopted this classification and included it into Legislative Decree $81 / 08$, which specifies the employer's obligations to replace the carcinogenic compound, when possible, and to reduce the exposure to the lowest technically possible level. According to these guidelines, a risk assessment must be reconsidered every three years, or in case of modifications of the workflow routine. It is important to underline that the regulation foresees that the employer also measures the presence of carcinogens or mutagens to verify the efficacy of the measures adopted. ${ }^{23}$

This work aimed at providing an example of a combined approach of environmental and biological monitoring carried out at a University Hospital setting in Southern Italy. Values of aerodispersed FA, resulting from environmental analyses, were on average very low, except for some environments, in which the concentrations slightly overcame the limit values established by NIOSH $($ TLV $=0.1 \mathrm{ppm})$, with a maximum value of $0.16 \mathrm{ppm}$ (macroscopic room, where bioptic samples were analysed). Accordingly, analyses performed on workers' urinary samples showed low values of FA, far from accepted TLV.

Statistical analysis of biological samples suggested a potential FA weekly accumulation. Although a different number of samples was analysed in each campaign, due to the turnover of department personnel, it is worth underlining that in 2018-2019 we noticed a lowering, albeit minimal, of FA accumulation levels between the beginning and the end of the working week.

However, it should be emphasized that the measurement of urinary formaldehyde levels in the long-term has severe limits, due to its very short half-life; therefore, other markers should be investigated to evaluate biological long-term backlog. Furthermore, AIDII guidelines consider as professional exposure limit values that are compatible with manufacturing companies, but not with environments such as hospitals, where the use of FA is used at much lower concentrations, but still potentially harmful. This led us to use the limit suggested by NIOSH, as it is the lowest. Nevertheless, our results clearly show that the concomitant analysis of air quality and actual workers' exposure is a key tool to allow optimization of work safety procedures, which must become routinely in hospitals. Combining environmental and biological monitoring is necessary to understand the state of workplaces, the efficacy of individual protection disposables, and the air filtering system. This is also important to assess the adherence of workers to good laboratory practices and preserve their health status.
Correspondence: Prof. Oriana Motta, Department of Medicine, Surgery and Dentistry, University of Salerno, Via Salvador Allende, 84081 Baronissi (SA), Italy.

Tel.+39.089.963083. E-mail: omotta@unisa.it

Key words: Biomonitoring; environmental monitoring; formaldehyde exposure; health and safety; occupational health practice.

Contributions: OM, VI, conceptualization; $\mathrm{BC}, \mathrm{AC}, \mathrm{CP}$, methodology; BC, FDR, GM, formal analysis, OM, VI, MC, FDC, AB, investigation; FDC, AF, AB, OM, VI, resources; $\mathrm{BC}, \mathrm{AC}$, FDR, data curation; $\mathrm{GM}, \mathrm{CP}$, original draft preparation; $\mathrm{OM}, \mathrm{VI}$, review and editing.

Conflict of interest: The authors declare that they have no competing interests, and all authors confirm accuracy.

Funding: This work was financially supported by Fondi di Ateneo per la Ricerca di Base (FARB 2017), University of Salerno.

Acknowledgments: The authors are grateful to AQUARIA Srl for providing passive and active samplers.

Ethics approval and consent to participate: this study falls within the framework of controls that workers perform routinely as part of the health surveillance programs and is not a clinical study. The data presented in this manuscript were produced by the San Giovanni di Dio and Ruggi d'Aragona hospital in Salerno, as part of the routine program of preventive medicine for monitoring workers exposed to organic solvents, as reported by the current law on workers (Legislative Decree 81 of 9 April 2008), and common good laboratory practices (GLP). No further withdrawals were made for the analyses reported in this study. For this reason, the opinion of the Ethics Committee was not necessary as it is not a clinical study or pharmacological treatment. The workers had already been informed by written communication that these samples were part of the normal practice of assessing exposure to chemicals and that the only analytes investigated in these procedures were those indicated in compliance with the aforementioned law. Workers data have been processed in accordance with the current laws on the protection of privacy and in accordance with the General Data Protection Regulation (GDPR) procedures n. 2016/679. Informed consent was not acquired from the workers as this procedure falls within the parameters indicated by the law for the protection of personal data Published in the Official Gazette no. 72 of 26 March 2012 (Register of measures n. 85 of 1 March 2012).

Availability of data and materials: All data generated or analyzed during this study are included in this published article.

Patient consent for publication: Not applicable.

Received for publication: 3 November 2020.

Accepted for publication: 14 February 2021.

${ }^{\circ}$ Copyright: the Author(s), 2021

Licensee PAGEPress, Italy

Journal of Public Health Research 2021;10:2012

doi:10.4081/jphr.2021.2012

This work is licensed under a Creative Commons Attribution NonCommercial 4.0 License (CC BY-NC 4.0).

\section{References}

1. Lewis BB, Chestner SB. Formaldehyde in dentistry: a review of mutagenic and carcinogenic potential. J Am Dent Assoc 1981;103:429-34

2. Wartew, GA The health hazards of formaldehyde. J Appl 
Toxicol 1983;3:121-6.

3. World Health Organisation. Formaldehyde Chapter 5.8. In: Air Quality Guidelines. Copenhagen WHO, Regional Office for Europe; 2001.

4. Restani P, Galli CL. Oral toxicity of formaldehyde and its derivatives. Crit Rev Toxicol 1991;21:315-28.

5. Ruyter IE. Release of formaldehyde from denture base polymers. Acta Odontol Scand 1980;38:17-27.

6. Heck HD, Casanova-Schmitz M, Dodd PB, et al. Formaldehyde $(\mathrm{CH} 2 \mathrm{O})$ concentrations in the blood of humans and Fischer-344 rats exposed to $\mathrm{CH} 2 \mathrm{O}$ under controlled conditions. Am Ind Hyg Assoc J 1985;46:1-3.

7. International Agency for Research on Cancer. IARC classifies formaldehyde as carcinogenic to humans. World Health Organization, Press Release $n^{\circ} 153-2004$.

8. Swenberg JA, Moeller BC, Lu K, et al. Formaldehyde carcinogenicity research: 30 years and counting for mode of action, epidemiology, and cancer risk assessment. Toxicol Pathol 2013;41:181-9.

9. Beall JR, Ulsamer AG. Formaldehyde and hepatotoxicity: A review. J Toxicol Environ Health 1984;14:1-21.

10. Tulpule K, Dringen R. Formaldehyde in brain: an overlooked player in neurodegeneration? J Neurochem 2013;127:7-21.

11. Shi SR, Liu C, Taylor CR. Standardization of Immunohistochemistry for formalin-fixed, paraffin-embedded tissue sections based on the antigen-retrieval technique: from experiments to hypothesis. J Histochem Cytochem 2007;55:105-9.

12. Motta O, Cucciniello R, Scicali C, Proto A. A study on the applicability of zinc acetate impregnated silica substrate in the collection of hydrogen sulfide by active sampling. Talanta 2014;128:268-72.

13. Cucciniello R, Proto A, La Femina R, et al. A new sorbent tube for atmospheric NOx determination by active sampling.
Talanta 2017;164:403-6.

14. Cucciniello R, Proto A, Rossi F, et al. An improved method for BTEX extraction from charcoal. Anal Methods 2015;7:4811-5.

15. Motta O, De Caro F, Quarto F, Proto A. New FT-IR methodology for the evaluation of $13 \mathrm{C} / 12 \mathrm{C}$ isotope ratio in Helicobacter pylori infection diagnosis. J Infect 2009;59:90-4.

16. Cucciniello R, Proto A, Alfano D, Motta O. Synthesis, characterization and field evaluation of a new calcium-based $\mathrm{CO} 2$ absorbent for radial diffusive sampler. Atmos Environ 2012;60:82-7.

17. Proto A, Cucciniello R, Rossi F, Motta O. Stable carbon isotope ratio in atmospheric $\mathrm{CO} 2$ collected by new diffusive devices. Environ Sci Pollut Res Int 2014;21:3182-6.

18. Motta O, Cucciniello R, La Femina R, et al. Development of a new radial passive sampling device for atmospheric NOX determination. Talanta 2018;190:199-203.

19. European Committee for Standardization. Diffusive samplers for the determination of concentrations of gases and vapours requirements and test methods. Part 2. Specific requirements and test methods. Norm EN 13528-2.

20. National Istitute for Occupational Safety and Health. NIOSH Manual of Analytical Method (NMAM). 2016. Accessed: September 4, 2020. Available from: https://www.cdc.gov/ niosh/nmam/default.html

21. Gentry PR, Rodricks JV, Turnbull D, et al. Formaldehyde exposure and leukemia: critical review and reevaluation of the results from a study that is the focus for evidence of biological plausibility. Crit Rev Toxicol 2013;43:661-70.

22. Italian Ministry of Health. Official Communication n. 57 of 22 June 1983. Uses of formaldehyde - Risks associated with possible methods of use.

23. Government of Italy. Legislative Decree n. 81 of 9 April 2008. Coordinated text with Legislative Decree n. 106 of 3 August 2009. 